\title{
Hubungan Kategori Berat Badan Lahir Rendah dengan Nilai Apgar di RSUP Dr. M. Djamil Padang Periode Januari- Desember 2013
}

\author{
Ebill Fuji Edison ${ }^{1}$, Eva Chundrayetti ${ }^{2}$, Eti Yerizel ${ }^{3}$
}

\begin{abstract}
Abstrak
Berat Badan Lahir Rendah (BBLR) adalah berat lahir < 2500 gram. BBLR merupakan prediktor utama angka kesakitan dan kematian bayi. Salah satu faktor yang dipengaruhi oleh berat lahir rendah adalah nilai Apgar. Nilai Apgar adalah hasil penilaian status atau evaluasi keadaan bayi lahir pada 1 dan 5 menit pertama Tujuan penelitian ini adalah menentukan hubungan BBLR dengan nilai Apgar. Penelitian analitik ini mengumpulkan data retrospektif rekam medis BBLR di RSUP Dr. M. Djamil Padang periode Januari-Desember 2013. Berat lahir dibagi menjadi 3 kategori, yaitu BBLR, BBLSR, BBLASR. Nilai Apgar dibagi menjadi 3 kategori yaitu, normal, asfiksia sedang, asfiksia berat. Data yang diperoleh dianalisis dengan menggunakan uji chi-square. Dari 111 kasus bayi BBLR, didapatkan kasus $\operatorname{BBLR}(81,3 \%)$, BBLSR (15,3\%), BBLASR (3,6\%). Dari nilai Apgar menit ke-1 didapatkan nilai apgar normal (58,6\%), asfiksia sedang $(29,7 \%)$, asfiksia berat (11,7\%). Pada nilai Apgar menit ke-5 didapatkan nilai Apgar normal $(75,7 \%)$, asfiksia sedang $(22,5 \%)$, asfiksia berat $(1,8 \%)$. Analisis bivariat chi-square menunjukkan nilai Apgar menit ke-1 memiliki hubungan yang signifikan dengan berat lahir rendah $(p=0,035)$. Nilai Apgar menit ke-5 tidak memiliki hubungan dengan berat lahir rendah $(p=0,285)$.
\end{abstract}

Kata kunci: berat badan lahir rendah, nilai Apgar

\section{Abstract}

Low Birth Weight (LBW) is a birth weight < 2500 gram. LBW is a major predictor of infant morbidity and mortality. LBW is a factor that can affect Apgar score. Apgar score is a test to assess baby's condition at $1^{\text {st }}$ minute and $5^{\text {th }}$ minute after birth. The objective of this study was to determine the relationship between low birth weight and Apgar score. This analytic research by obtaining retrospective data from medical records of $L B W$ babies at RSUP Dr. M. Djamil Padang from January until December 2013. Birth weight was devided into three categories; BBLR, BBLSR, BBLASR. Apgar score was divided into three categories; normalvigorous baby, light asphyxia and severe asphyxia. Among 111 cases of LBW, BBLR (81.3\%), BBLSR (15.3\%), BBLASR (3.6\%) were found in this study. Normal Apgar score (58.6\%), Light asphyxia (29.7\%), and severe asphyxia (11.7\%) were found in $1^{\text {st }}$ minute Apgar score. Normal Apgar score (75.7\%), light asphyxia (22.5\%), and severe asphyxia (1.8\%) were found in $1^{\text {st }}$ minute Apgar score. Chisquare test showed $5^{\text {th }}$ minute of Apgar score was statistically significant to $L B W(p=0.035)$. Chi square test showed $5^{\text {th }}$ minute of Apgar score was not statistically significant to $L B W(p=0.285)$.

Keywords: low birth weight, Apgar score

Affiliasi penulis: 1. Pendidikan Dokter FK UNAND (Fakultas Kedokteran Universitas Andalas Padang), 2. Bagian IImu Kesehatan Anak FK UNAND, 3. Bagian Biokimia FK UNAND

Korespondensi: Ebill Fuji Edison; Email: ebilldua2@gmail.com, Telp: $+6282170052049$

\section{PENDAHULUAN}

Berat Badan Lahir Rendah (BBLR) merupakan salah satu faktor utama yang berpengaruh terhadap kematian neonatal. ${ }^{1}$ BBLR adalah bayi dengan berat lahir kurang dari 2500 gram tanpa memandang masa 
gestasi, dimana berat lahir diukur dalam waktu 1 jam setelah kelahiran. ${ }^{2}$ Di Indonesia, 56\% kematian bayi terjadi pada masa neonatal, sebagian besar terjadi pada 0-6 hari (78,5\%). Hasil Survey Demografi dan Kesehatan Indonesia (SDKI) tahun 2007, AKB masih 34/1.000 kelahiran hidup, sedangkan target Millenium Development Gold (MDG) 2015 adalah menurunkan AKB kelahiran hidup menjadi 23 per 1000 kelahiran hidup. ${ }^{3}$ Bayi Berat Lahir Rendah juga termasuk faktor utama dalam peningkatan morbiditas, dan disabilitas neonatus, bayi, dan anak serta memberikan dampak jangka panjang terhadap kehidupannya di masa depan $^{4}$. Hasil penelitian di daerah Jawa Barat menunjukkan bahwa BBLR menunjukkan kurva pertumbuhan yang mendatar setelah usia 6 bulan. $^{5}$ Berat lahir juga salah satu faktor yang mempengaruhi nilai Apgar. Bayi dengan berat lahir dibawah 2500 gram dan diatas 2500 gram memiliki nilai Apgar yang berbeda pada 1, 5, dan 10 menit pertama, dimana bayi dengan berat lahir diatas 2500 gram memiliki nilai Apgar yang lebih tinggi dari bayi dengan berat lahir dibawah 2500 gram. $^{6}$ Kematian neonatal juga meningkat seiring dengan rendahnya nilai Apgar pada menit ke-10 dan menit ke-5 pada bayi aterm maupun preterm. ${ }^{7,8}$ Rendahnya nilai Apgar pada menit pertama memiliki pengaruh yang lebih besar dengan kematian janin. ${ }^{9}$ Berdasarkan permasalahan di atas maka peneliti ingin mengetahui apakah BBLR dapat mempengaruhi hasil pemeriksaan nilai Apgar di RSUP Dr. M. Djamil Padang

\section{METODE}

Penelitian ini merupakan penelitian analitik. Penelitian dilakukan di Bagian Rekam Medik RSUP Dr. M. Djamil Padang Maret 2014-Juli 2014.

Populasi penelitian adalah seluruh bayi lahir yang terdata di rekam medis RSUP Dr. M. Djamil Padang periode 1 Januari 2010-31 Desember 2013. Sampel pada penelitian ini diambil dengan teknik total sampling yaitu seluruh populasi dinyatakan sebagai sampel.

Data yang diambil adalah berat lahir dan nilai Apgar. Pengolahan data dilakukan secara manual, dilakukan editing terhadap semua variabel yang diteliti kemudian dihitung jumlahnya dengan cara tabulasi. Data dianalisa dengan menggunakan uji Chi-Square.
HASIL

Didapatkan 1710 kelahiran periode 1 Januari 2010 sampai 31 Desember 2013 melalui data rekam medik pasien.

Tabel 1. Distribusi frekuensi angka kelahiran di RSUP Dr. M. Djamil

\begin{tabular}{lcc}
\hline Angka Kelahiran & $\mathbf{n}$ & $\%$ \\
\hline Non BBLR & 1510 & 88 \\
\hline BBLR & 200 & 12 \\
\hline Total & 1710 & 100 \\
\hline
\end{tabular}

Dari 1710 angka kelahiran, 200 kasus BBLR yang ada, dilakukan pencatatan nilai Apgar.

Tabel 2. Distribusi frekuensi angka kelahiran BBLR

\begin{tabular}{lcc}
\hline Klasifikasi BBLR & $\mathbf{n}$ & $\%$ \\
\hline BBLR & 90 & 81,3 \\
\hline BBLSR & 17 & 15,3 \\
\hline BBLASR & 4 & 3,6 \\
\hline Total & 111 & 100 \\
\hline
\end{tabular}

Data diatas dapat disimpulkan bahwa pada periode Januari 2013 - Desember 2013 di RSUP Dr. M. Djamil Padang kasus BBLR lebih sering terjadi dibandingkan dengan BBLSR (Bayi Berat Lahir Sangat Rendah) dan BBLASR (Bayi Berat Lahir Amat Sangat Rendah) .

Tabel 3. Distribusi frekuensi nilai Apgar menit ke-1 pada BBLR di RSUP Dr. M. Djamil periode Januari 2013 - Desember 2013

\begin{tabular}{llc}
\hline Nilai Apgar Menit ke-1 & $\mathbf{n}$ & $\%$ \\
\hline Normal (7-10) & 65 & 58,6 \\
\hline Asfiksia sedang (4-6) & 33 & 29,7 \\
\hline Asfiksia berat (0-3) & 13 & 11,7 \\
\hline Total & 111 & 100 \\
\hline
\end{tabular}

Ada 111 kasus yang diteliti, ditemukan nilai Apgar normal 65 kasus (58,6\%), Asfiksia sedang 33 kasus (29,7\%), Asfiksia berat 13 kasus (11,7\%) 
Tabel 4. Distribusi frekuensi nilai Apgar menit ke-5 pada BBLR di RSUP Dr. M. Djamil periode Januari 2013 - Desember 2013

\begin{tabular}{lcc}
\hline Nilai Apgar Menit ke-5 & $\mathbf{n}$ & $\%$ \\
\hline Normal (7-10) & 84 & 75,7 \\
\hline Asfiksia sedang (4-6) & 25 & 22,5 \\
Asfiksia berat (0-3) & 2 & 1,8 \\
Total & 111 & 100 \\
& & \\
\hline
\end{tabular}

Berdasarkan Tabel 4, dari 111 kasus yang diteliti, ditemukan nilai Apgar normal 84 kasus (75,7\%), Asfiksia sedang 33 kasus (22,5\%), Asfiksia berat 13 kasus $(1,8 \%)$.

Tabel 5. Hubungan Bayi Berat Lahir Rendah dengan nilai Apgar asfiksia dan tidak asfiksia menit ke-1 di RSUP Dr. M. Djamil Padang periode Januari 2013 Desember 2013

\begin{tabular}{|c|c|c|c|c|c|c|c|}
\hline \multirow{3}{*}{$\begin{array}{l}\text { Kategori } \\
\text { BBLR }\end{array}$} & \multicolumn{4}{|c|}{ Derajat asfiksia } & \multirow{2}{*}{\multicolumn{2}{|c|}{ Total }} & \multirow{3}{*}{$\mathbf{p}$} \\
\hline & \multicolumn{2}{|c|}{$\begin{array}{c}\text { Tidak } \\
\text { asfiksia }\end{array}$} & \multicolumn{2}{|c|}{ Asfiksia } & & & \\
\hline & $\mathbf{n}$ & $\%$ & $\mathbf{n}$ & $\%$ & $n$ & $\%$ & \\
\hline BBLR & 57 & 63 & 33 & 37 & 90 & 100 & \\
\hline & & & & & & & 0,035 \\
\hline BBLSR & 8 & 38 & 13 & 62 & 21 & 100 & \\
\hline Total & 65 & 58 & 46 & 42 & 111 & 100 & \\
\hline
\end{tabular}

Hasil uji chi-square didapatkan nilai $p=0,035$, sedangkan nilai $\mathrm{p}$ yang dianggap bermakna adalah < 0,05 . Hal ini berarti terdapat hubungan yang signifikan antara BBLR dengan nilai Apgar menit ke -1. Dalam hal ini, berat lahir rendah dapat mempengaruhi nilai Apgar menit ke -1 .

Berdasarkan Tabel 6, didapatkan nilai $p=0,285$, sedangkan nilai $p$ yang dianggap bermakna adalah < 0,05 . Hal ini berarti tidak terdapat hubungan yang signifikan antara BBLR dengan nilai Apgar menit ke 5. berat lahir rendah tidak mempengaruhi nilai Apgar menit ke -5
Tabel 6. Hubungan Bayi Berat Lahir Rendah dengan nilai Apgar asfiksia dan tidak asfiksia menit ke-5 di RSUP Dr. M. Djamil Padang periode Januari 2013 Desember 2013

\begin{tabular}{|c|c|c|c|c|c|c|c|}
\hline \multirow{4}{*}{$\begin{array}{l}\text { Kategori } \\
\text { BBLR }\end{array}$} & \multicolumn{4}{|c|}{ Derajat asfiksia (\%) } & \multirow{2}{*}{\multicolumn{2}{|c|}{ Total }} & \\
\hline & \multirow{2}{*}{\multicolumn{2}{|c|}{$\begin{array}{c}\text { Tidak } \\
\text { asfiksia }\end{array}$}} & \multirow{2}{*}{\multicolumn{2}{|c|}{ Asfiksia }} & & & p \\
\hline & & & & & & & \\
\hline & $\mathbf{n}$ & $\%$ & $\mathbf{n}$ & $\%$ & $\mathbf{n}$ & $\%$ & \\
\hline BBLR & 70 & 77 & 20 & 23 & 90 & 100 & \\
\hline BBLSR & 14 & 66 & 7 & 26 & 34 & 100 & 0.285 \\
\hline Total & 84 & 75 & 27 & 25 & 111 & 100 & \\
\hline
\end{tabular}

\section{PEMBAHASAN}

Berat badan lahir rendah (BBLR) atau Low Birth Weight (LBW) adalah berat badan lahir yang kurang dari 2500 gram tanpa memandang usia gestasi. $^{2}$ BBLR diklasifikasikan dalam dua golongan berdasarkan perbandingan berat badan lahir dengan usia gestasi bayi saat lahir yaitu prematuritas murni dan dismaturitas. Prematuritas murni adalah bayi yang lahir dengan usia gestasi kurang dari 37 minggu dengan berat badan sesuai dengan usia gestasinya. Dismaturitas adalah bayi yang lahir dengan berat badan kurang dari berat potensial yang harus dicapai dalam usia gestasi tertentu. ${ }^{10}$ Berdasarkan hasil pada Tabel 2, didapatkan kejadian bayi BBLR sebanyak 111 kasus, dengan BBLR sebanyak 90 kasus (81,3\%), BBLSR sebanyak 17 kasus (15,3\%), dan BBLASR sebanyak 4 kasus (3,6\%).

Pada penelitian yang dilakukan di RSUP Dr. M. Djamil Padang periode Januari 2013-Desember 2013, berdasarkan hasil pada Tabel 3, diperoleh hasil bahwa nilai Apgar normal (58,6\%) memiliki distribusi yang lebih besar dari asfiksia sedang dan asfiksia berat pada pemeriksaan nilai Apgar menit ke -1 bayi BBLR. Nilai Apgar normal juga memiliki distribusi yang lebih besar pada pemeriksaan nilai Apgar menit ke-5 $(75,7 \%)$. 
Hasil penelitian pada Tabel 3, pada menit ke-1 sebanyak 58,6\% bayi BBLR dengan nilai Appgar normal, 29,7\% bayi BBLR dengan asfiksia sedang, dan $11,7 \%$ bayi BBLR dengan asfiksia berat. Berdasarkan hasil penelitian pada Tabel 4, pemeriksaan nilai Apgar pada menit ke-5 bayi BBLR didapatkan sebanyak $75,7 \%$ bayi BBLR dengan nilai Apgar normal, 22,5\% bayi BBLR dengan asfiksia sedang, dan 1,8\% bayi BBLR dengan asfiksia berat.

Pada penelitian ini digunakan analisis bivariat chi-square untuk melihat hubungan antara variabel bebas dan variabel terikat. Pada nilai Apgar menit ke-1 didapatkan sebaran distribusi frekuensi responden yang tidak merata dan terdapat jumlah $<5$ responden pada beberapa sel sehingga uji chi-square tidak layak digunakan. Hal dapat terjadi karena banyaknya sampel eksklusi sehingga data yang diperoleh masih belum bisa menggambarkan keadaan yang sebenarnya. Oleh sebab itu dilakukan supresi table 2x2 untuk memenuhi syarat uji chi-square dan mendapatkan nilai $p$ yang valid. Klasifikasi berat lahir rendah dibagi atas BBLR dan BBLSR. Interpretasi nilai Apgar dibagi atas tidak asfiksia dan asfiksia.

Berdasarkan hasil analisis bivariat dengan uji chi-square pada Tabel 5 yang dilakukan pada faktor risiko yang diteliti, didapatkan hubungan yang signifikan pada nilai apgar menit ke-1 $(p=0,035)$.

Bayi BBLR preterm cenderung memiliki nilai Apgar yang lebih rendah daripada bayi cukup bulan karena imaturitas neurologis mempengaruhi tonus otot, memperlambat reflek dan warna merah kebiruan pada kulit. ${ }^{11}$ Selain itu berat lahir rendah pada bayi akan menggangu kematangan organ dan tubuh bayi yang belum sempurna (prematuritas) sehingga dapat mengakibatkan nilai apgar rendah. Kematangan dan fungsi organ juga dapat dipengaruhi oleh gangguan pertumbuhan intrauterine atau Intra Uterine Growth Restriction (IUGR). ${ }^{12}$

Pada nilai Apgar menit ke-5 didapatkan sebaran distribusi frekuensi responden yang tidak merata dan terdapat jumlah $<5$ responden pada beberapa sel sehingga uji chi-square tidak layak digunakan. Hal dapat terjadi karena banyaknya sampel eksklusi sehingga data yang diperoleh masih belum bisa menggambarkan keadaan yang sebenarnya. Oleh sebab itu dilakukan supresi table 2x2 untuk memenuhi syarat uji chi-square dan mendapatkan nilai $p$ yang valid. Klasifikasi berat lahir rendah dibagi atas BBLR dan BBLSR. Interpretasi nilai Apgar dibagi atas tidak asfiksia dan asfiksia.

Berdasarkan hasil analisis bivariat dengan uji chi-square pada Tabel 6 yang dilakukan pada faktor risiko yang diteliti, tidak didapatkan hubungan yang signifikan pada nilai apgar menit ke-5 ( $p=0,285)$. Penelitian yang dilakukan Onama pada tahun 2003 terhadap 1479 bayi di Uganda, tidak menemukan adanya hubungan yang signifikan antar berat lahir dengan nilai apgar $(p=0,08) .{ }^{13} \mathrm{Hal}$ ini bisa disebabkan karena adanya faktor lain yang mempengaruhi nilai Apgar selain berat lahir. Usia kehamilain, obat-obatan yang digunakan oleh ibu, dan kondisi kardiorespirasi serta neurologis neonatus juga dapat mempengaruhi nilai Apgar. ${ }^{14}$ Proses kelahiran, primipara, usia kehamilan, riwayat penyakit selama kehamilan, dan usia kehamilan, serta tindakan resusitasi juga merupakan faktor yang mempengaruhi nilai Apgar. Nilai Apgar menit ke-5 juga digunakan untuk mengevaluasi apakah tindakan resusitasi sudah adekuat. $^{15}$

\section{KESIMPULAN}

Bayi BBLR memiliki hubungan dengan nilai Apgar pada menit ke-1, tetapi bayi BBLR tidak memiliki hubungan dengan nilai Apgar pada menit ke $5(p=0,285)$.

\section{DAFTAR PUSTAKA}

1. Dinas Kesehatan. Riset kesehatan dasar. Jakarta: Badan Penelitian dan Pengembangan Kesehatan, Departemen Kesehatan Republik Indonesia; 2012.

2. Kosim MS, Yunanto A, Dewi R, Sarosa GI, Usman A. Gangguan napas pada bayi baru lahir. Dalam: Buku Ajar Neonatologi . Edisi ke-1. Jakarta: IDAI; 2012. hlm.126-46.

3. Kementerian Kesehatan Republik Indonesia. Manajemen bayi berat lahir rendah (BBLR) untuk bidan di desa. Jakarta: Direktorat Bina Gizi dan Kesehatan Ibu dan Anak; 2011.

4. Kementerian Kesehatan Republik Indonesia. Profil kesehatan Indonesia 2009. Jakarta: Departemen Kesehatan Indonesia; 2010. 
5. Rahayu S, Sofyaningsih M. Pengaruh BBLR (berat badan lahir rendah) dan pemberian ASI eksklusif terhadap perubahan status stunting pada balita di kota dan kabupaten Tanggerang Provinsi Banten. 2011:160-9.

6. Rahi E, Baneshi MR, Mirkandar E, Maghsoudi HS, Rastegari A. A comparison between Apgar score and birth weight in infants of addicted and nonaddicted mothers. Addict \& Health, Winter \& Spring. 2011;3(2):61-7.

7. Casey MB, McIntire DD, Leveno JK. The continuing value of the apgar score for the assessment of mewborn infants. $\mathrm{N}$ Engl $\mathrm{J}$ Med. 2001;344(7):467-71.

8. Misra PK. Outcome in relation to apgar score in term neonates. Indian Pediatric Journal. 1994;31(3):1215-8.

9. Ehresnstein V. Assosiation of Apgar score with death and neurologic diasbility. Journal of clinical epidemiology. 2009:45-53.

10. Surasmi A, Handayani S, Kusuma HN. Perawatan Bayi Risiko Tinggi, Jakarta: EGC; 2003.

11. Benson RC, Pernoll ML. Buku saku obstetri dan ginekologi. Edisi ke-9. Jakarta: EGC; 2008.

12. Dhaar GM, Robbani I. Foundations of community medicine. Edisi ke-2. Philadelphia: Elsevier; 2008.

13. Onama C, Tumwine K. Immediate outcome of babies with low Apgar score in Mulago hospital Uganda. East African Medical Journal. 2003; 80: 22-9.

14. Papile L. The Apgar score in the $21^{\text {st }}$ century. $\mathrm{N}$ Eng J Med. 2001;344(7):519-20.

15. Matondang, Wahidayat, Sastroasmoro. Pemeriksaan fisis neonatus. Dalam: Diagnosis Fisis pada Anak. Edisi ke-2. Jakarta: CV Sagung Seto;2003. hlm. 146-7. 